\title{
A crise do sistema soviético e o fim da Guerra Fria
}

\author{
The Soviet System crisis and the end of Cold War
}

Sidnei José Munhoz*

Resumo: Este artigo tem como propósito examinar a crise do sistema soviético e as estratégias desenvolvidas pelo governo Gorbachev para redirecionar a economia e a política soviética com o objetivo de resolver os principais problemas que afetavam a URSS durante os anos 1980. Em adição, serão analisados os problemas encontrados por Gorbachev para implementar as reformas que tanto a União Soviética necessitava e a expansão da crise que culminou na dissolução da URSS.

Palavras-chave: Guerra Fria, União Soviética, Gorbachev, Perestroika, Glasnost

\begin{abstract}
The purpose of this paper is to examine the crisis of Soviet system, and the strategies developed by Gorbachev government to redirect Soviet economy and policy in order to solve the main problems that affected the USSR during the 1980s. In addition, it will be scrutinized the obstacles found by Gorbachev to promote the restructurings that Soviet Union required, and the expansion of the crisis that culminated in the dissolution of the USSR.
\end{abstract}

Keywords: Cold War, Soviet Union, Gorbachev, Perestroika, Glasnost.

\footnotetext{
* Doutor em História Econômica pela Universidade de São Paulo. É Professor Associado da Universidade Estadual de Maringá, Maringá/PR, Brasil e docente do Programa de Pósgraduação em História (PPH-UEM). Bolsista de Produtividade em Pesquisa do CNPq (Nível 2). E-mail: sidneimunhoz2010@gmail.com

(c) EY Direito autoral e licença de uso: Este artigo está licenciado sob uma Licença Creative Commons. Com essa licença você pode compartilhar, adaptar, para qualquer fim, desde que atribua a autoria da obra, forneça um link para a licença, e indicar se foram feitas alterações.
} 


\section{Introdução}

As reflexões apresentadas neste artigo precisam ser situadas em um contexto histórico marcado nas últimas quase três décadas por mudanças relevantes no campo da diplomacia, além de outras inquietações no campo das relações internacionais. A arquitetura de poder global edificada durante o longo conflito de dimensões globais conhecido como Guerra Fria se dissipou. Após a crise e a falência dos regimes pró soviéticos da Europa Oriental e, na sequência, a desagregação da própria União Soviética, deu-se o alargamento das chamadas fronteiras ocidentais e do modelo de capitalismo e de democracia liberal liderados pelos EUA.

No contexto em que um dos contendores da Guerra Fria deixava de existir, o modelo bipolar ${ }^{1}$ que grosso modo operou durante aquele conflito não deu origem a um sistema multipolar. Sobre essa problemática, G. John Ikenberry $^{2}$ defende a perspectiva de que, com o fim da Guerra Fria, os EUA passaram a atuar como uma potência unipolar. Discordo do autor, pois, embora reconheça a possibilidade da existência de uma supremacia ou da preponderância do poder estadunidense no campo militar, acredito que a complexidade da atual fase de expansão do capitalismo negue a tese da unipolaridade. Sublinho a necessidade de considerar os diferentes campos por intermédio dos quais as nações se relacionam nesse complexo cenário. Merecem destaque os campos do comercio internacional, das instituições políticas e da cultura. Dessa perspectiva, a noção de unipolaridade torna-se insustentável, uma vez que existe uma grande interdependência entre as nações, apesar da enorme preponderância do poder estadunidense.

Ainda início da década de 1990, intelectuais associados aos Think Tanks estadunidenses preconizavam uma nova era de tranquilidade e opulência, derivada da percepção de que com o fim da Guerra Fria, o mundo atravessava um momento promissor. Chegou-se a proclamar o fim da História, uma tese esdrúxula elaborada por Francis Fukuyama, que de modo célere ganhou repercussão global e produziu uma excitação acadêmica alavancada pela mídia, mas logo perdeu vigor frente a críticas contundentes ${ }^{3}$. Naquele contexto, afiançou-se um consenso por meio do qual só haveria um caminho a seguir e garantiu-se que ele levaria à melhoria dos padrões de bem-estar social, como resultado de uma nova onda de desenvolvimento econômico conduzida pelos EUA.

Sedimentados aqueles eventos e frustradas muitas daquelas promessas, ao contrário do proclamado, houve a expansão de conflitos em diferentes regiões do planeta. Muitos desses conflitos, regra geral com algum tipo de envolvimento dos EUA, espalharam-se pelas fronteiras do chamado mundo ocidental e nas bordas das áreas que em passado recente estavam sob a influência da URSS. Agora, sem a antiga oponente que obstaculizava a sua ação durante a Guerra Fria, os EUA e a Otan expan- 
diam a sua influência e o seu controle sobre áreas anteriormente situadas na órbita soviética.

No Ocidente, durante a Guerra Fria, construiu-se um discurso convincente sobre a existência de um projeto de dominação mundial soviético. O fracasso do modelo soviético permite descortinar mais claramente os limites daquela construção e abre janelas para a percepção da questão a partir de outra ótica.

\section{Uma aproximação ao tema}

Até recentemente, estava consolidada na literatura especializada a interpretação de que, após décadas de contínuo crescimento em patamares superiores àqueles verificados no mundo capitalista, a URSS começou a apresentar, a partir da década de 1960, uma tendência à redução no seu ritmo de desenvolvimento. Dessa forma, a distância entre o mundo capitalista e o soviético, que no pós-II Guerra Mundial estava continuamente a diminuir, experimentou certa estabilidade por volta de meados da década de 1960. No entanto, ao longo da década de 1970, a distância entre os dois mundos voltou a aumentar, a princípio de forma modesta e, posteriormente, de modo mais intenso. Em grande medida, o crescimento soviético das décadas anteriores, alicerçado em um modelo de produção extensiva, com o aumento do número de unidades produtivas e da intensificação do ritmo do trabalho e das horas laboradas estava, a se esgotar"

Desse modo, na URSS, alargava-se a produção sem que necessariamente houvesse o aumento da produtividade lastreada no desenvolvimento de novas tecnologias e na melhor qualificação da força de trabalho. Até o início da década de 1970, a percepção dessas tendências não era muito visível fora da URSS e, naquele país, era conhecida somente por um grupo muito restrito dos dirigentes do Partido Comunista. Entre 1965 e 1970, os sinais da vitalidade econômica soviética, apesar de já indicarem uma queda no seu ritmo de crescimento, ainda eram bastante expressivos. O país contabilizou um crescimento industrial anual médio ao redor de $8,4 \%$. No entanto, dez anos depois, essa média havia recuado para 3,5\%. Assim, os sonhos de se equipararem ou superarem a economia dos EUA naufragaram ${ }^{5}$. Para Angelo Segrillo, a emergência da Terceira Revolução Tecnológica no Ocidente com a definição de novos padrões organizacionais da produção industrial baseados no toyotismo haveria sido um fator fundamental para que a economia soviética começasse a perder terreno. Para o autor, o modelo de produção soviético conseguia fazer frente à produção fordista prevalente Ocidente entre as décadas de 1930 e o início da década de 1960, mas não tinha como competir com a nova produção industrial baseada na flexibilidade, nos fluxos mais horizontais de informação e comando e, em especial, na proeminência atribuída à qualidade da produção ${ }^{6}$. Além disso, nas nações líderes do mundo capitalista, o desenvolvimento pujante da 
microeletrônica, da informática, da robótica e da automação ampliavam ainda mais essa distância.

Como afirmou Mikhail Gorbachev, durante a segunda metade da década de 1970 ficou muito claro algo que parecia inexplicável aos soviéticos, pois o país começou a perder impulso. Naquele contexto, a economia principiou a apresentar sinais de fadiga e deterioração, externados pelo aumento das dificuldades e pelos sucessivos fracassos nas metas traçadas pelos organismos de planejamento soviéticos; esses problemas não foram solucionados e se multiplicaram, de forma que passaram a funcionar como um freio a impedir o desenvolvimento econômico e social do país. Enquanto o restante do mundo estava a experimentar uma nova revolução científica e tecnológica, a União Soviética entrava em um processo de estagnação econômica? ${ }^{7}$.

Para Lenina Pomeranz, durante a era Gorbachev emergiram sérias críticas às estatísticas de que o país dispunha. V. Seliunin iniciou a polêmica sobre a distorção as estatísticas soviéticas ao publicar, em 1987, (Novi Mir, n.2) o artigo Lukavaia Tsifra (O dado enganoso). Posteriormente, Nicolai Shmelev e Vladimir Popov deram continuidade ao debate ao publicar The Turning Point. Revitalizing the Soviet Economy (1990). Segundo esses autores, havia erros nos procedimentos estatísticos e observava-se que a superestimação nos dados oficiais relativos à produção havia sido sistemática a partir do final da década de 1920. Para os autores mencionados, essas distorções perduraram nas décadas seguintes e, em especial, tornam-se ainda mais evidentes na década de $1970^{8}$.

Segundo os estudiosos, não se tratava de erro humano isolado, mas de problemas sistêmicos com as estatísticas existentes na URSS. De forma a atualizar o debate, lembro que Alec Nove pulicou The economics of feasible socialism revisited, em 1991, quando apresentou um mapeamento dos novos questionamentos às estatísticas soviéticas ${ }^{9}$. Em outro texto, Alec Nove analisa a retomada do vigor no campo das análises econômicas e das estatísticas soviéticas durante a década de 1980. Alec Nove aponta a importância dos trabalhos de Tatiana Zalavskaia, Abel Aganbegyan, Grigory Khanin, Vasily Selyunin, Andrei Illarionov, entre outros. Esses autores, de formas distintas, apresentaram uma crítica em comum ao tratamento estatístico existente no período soviético. Alguns deles, como Khanin e Selyunin, afirmaram que entre 1928 e 1986, enquanto os dados oficiais apresentavam um crescimento da economia em cerca de 90 vezes, a realidade era de que ela havia crescido apenas entre 6 e 7 vezes, um dos piores dados do mundo, segundo os autores. Andrei Illarionov, sumarizado por Alec Nove, afirma que o país apresentava padrões de países subdesenvolvidos e indicadores sociais similares aos da Venezuela, de Portugal e da Grécia ${ }^{10}$.

Lenina Pomeranz examina os dados apresentados por Seliunin, Nicolai Shmelev, Vladimir Popov e outros autores que tratam as estatísticas econômicas soviéticas. Pomeranz afirma que, apesar de os dados haverem 
sido superestimados, o crescimento econômico soviético haveria ocorrido a taxas elevadas. Em relação a esse debate gostaria de tecer algumas últimas considerações que me parecem pertinentes. Do meu ponto de vista, caso Seliunin e Khanin estivessem corretos, o crescimento econômico soviético haveria sido diminuto ao longo de seis décadas. Se essa assertiva está correta, como explicar que uma nação com crescimento tão insignificante pudesse haver se reconstruído após a devastação de duas guerras mundiais, de uma guerra civil, dos extermínios stalinistas e apresentar-se como a segunda potência global? Certamente, muito mais estudos serão necessários para compreender no detalhe como se comportou a economia soviética. A considerar a comparação de dados da URSS com a Venezuela, com Portugal e com a Grécia, sublinhase que a União Soviética possuía em seu interior contradições marcantes. De um lado, era a segunda potência global, com setores altamente desenvolvidos (militar e energético, por exemplo) e outros em níveis incipientes, próximos dos padrões do chamado Terceiro Mundo. Assim, se empregarmos a terminologia questionável e desgastada, era a líder do Segundo Mundo, e, de forma paradoxal, apresentava perfis de Primeiro e Terceiro Mundo entrelaçados em seu interior.

No que se refere à intensificação dos problemas econômicos soviéticos nas últimas décadas que antecederam à sua desagregação, deve-se observar o impacto da crise do petróleo iniciada em 1973. A brusca elevação dos preços do barril de petróleo no mercado internacional mascarou a situação da economia soviética, uma vez que o país empregou as receitas geradas com a exportação do combustível fóssil para importar produtos de forma a atender às demandas internas. Além disso, esses recursos serviram para financiar os déficits tanto internos quanto dos Estados ligados à sua esfera de influência. Assim, no momento em que os sinais da crise do sistema soviético tendiam ganhar relevância, eles foram mascarados pelo ingresso do dinheiro proveniente da venda do petróleo ${ }^{11}$.

De fato, naquele momento, a percepção da sociedade soviética era de que estava a haver uma sensível melhora nas condições de vida, com a redução das filas para acesso a muitos produtos de consumo. Assim, segundo o mesmo autor, perdeu-se a oportunidade de reformar o sistema quando ainda era possível e havia recursos para isso. Quando, entre o início e meados da década de 1980, os preços do petróleo despencaram, os sinais da crise tornaram-se evidentes, mas, naquele contexto, a situação era muito mais grave e o país não mais dispunha de recursos abundantes para financiar as reformas necessárias.

O exposto não implica que a existência de recursos garantisse a realização das reformas sem embates no interior do sistema. Nesse ponto, ressalta-se a constituição de uma imensa máquina burocrática que, ao longo de décadas, se autonomizou dos interesses reais da sociedade. Essa nova elite passou a atuar na defesa dos seus interesses de grupo ou de classe, pois, como caracterizam alguns críticos situados no campo do marxismo, essa elite, embora 
não fosse proprietária dos meios de produção, era a sua beneficiária direta. Reformar o sistema implicava afetar esses interesses e, dessa forma, quando alguns pretendiam reformar, muitos se opunham mesmo que de forma velada ou inercial a eventuais projetos reformistas. Resistências às mudanças faziam parte do modus operandi das elites soviéticas. Apenas para assinalar, uma vez que esse não é o foco do problema em lide, Kruschev ensaiou reformas, mesmo que tímidas, durante o seu governo e enfrentou considerável resistência aos seus projetos.

A resistência aos projetos reformistas propostos por Kruschev era proveniente da ausência de planejamentos adequados que levavam à desorganização do sistema produtivo e de uma percepção de impulsividade do líder ${ }^{12}$. Enquanto as reformas apresentaram algum resultado palpável, Kruschev conseguiu manter uma unidade mínima que o sustentava. Contudo, quando se deparou com resultados adversos, muitos deles procedentes dos fracassos da reforma agrícola por ele proposta, a sua base de sustentação foi rapidamente erodida e, desse modo, foram criadas as condições para a sua remoção do poder, por meio de um golpe palaciano. Segundo Daniel Aarão Reis Filho, os conspiradores repudiavam em Kruschev o que denominavam como um reformismo voluntarista e inconsequente. Assim, afirmavam defender a realização de reformas, mas com estabilidade e equilíbrio ${ }^{13}$.

No mundo soviético, a inércia, as resistências e outros problemas de vulto limitavam ou impediam a realização das necessárias reformas. Além disso, mesmo que essas barreiras fossem vencidas, emergia o problema relacionado à confiabilidade das informações econômicas. Alec Nove aponta autores com diferentes pontos de vista que aderem à ideia de que, de fato, não se podia falar em planejamento na União Soviética (Eugene Zaleski, J. Wilhelm, Hillel Ticktin). Segundo Alec Nove, eles argumentam, cada um a seu modo, que, regra geral, os planos não eram cumpridos, as diretrizes eram objeto de barganha, as informações eram desencontradas, distorcidas e repletas de inconsistências ${ }^{14}$.

Outra questão merece consideração na análise da emergência da crise soviética em meados da década de 1980. A corrida armamentista imposta pelos EUA no contexto da Guerra Fria, que perdurou por cerca de quatro décadas, drenou vultosos recursos que poderiam ser investidos no desenvolvimento do país. Segundo essa perspectiva, esses recursos foram despendidos em duas grandes vertentes.

A primeira vertente refere-se ao campo militar, onde a URSS buscou a paridade estratégica com os EUA. Com uma produção de riquezas que, no início da década de 1960, equivalia à aproximadamente a metade daquela verificada nos EUA, a União Soviética gastou por anos a fio, em termos proporcionais ao seu PIB, o dobro do que despendia a potência rival. Sublinha-se em relação a esse tópico que, se os dados estatísticos soviéticos foram, de fato, superestimados em demasia, como apontam autores já mencionados, o gasto 
proporcional foi ainda muito maior. Desse ponto de vista, a contínua sangria de recursos para atender à crescente demanda no campo militar haveria produzido efeitos perversos na economia do país.

A segunda vertente relaciona-se à crença de ambas as potências de que o mundo passava por uma fase especial e da avaliação de que a história estava do seu lado. Em decorrência dessa percepção, EUA e URSS competiram, por intermédio de projetos de modernização divergentes, no assim chamado Terceiro Mundo, entre as décadas de 1950 e 1960. Como resultado dessa disputa, vultosos investimentos efetuados pela URSS no Sudão, na Indonésia e em Gana, apenas para citar alguns exemplos, foram perdidos em consequência de golpes de Estado que levaram à deposição dos regimes associados ao Kremlin.

No contexto da Guerra Fria, a disputa política soviética com os EUA foi sempre onerosa para os cofres de Moscou, mesmo quando os regimes alinhados à URSS se tornaram estáveis, como foi caso de Cuba. De forma adicional, havia outras dificuldades na implementação dessas políticas de apoio aos chamados regimes amigos, pois muitas vezes não havia a reciprocidade esperada. Um exemplo dessa situação era o Egito, comandado por Nasser. A despeito do apoio recebido, Nasser não se posicionava de modo claro em relação às disputas das duas grandes potências. Em paralelo, no Egito, o próprio Partido Comunista sofria severa repressão durante o governo Nasser ${ }^{15}$. Como resultado dessas e de outras experiências negativas, os soviéticos começaram a revisar a sua política para o Terceiro Mundo por volta da metade da década de 1960.

Nesse ponto, ainda é importante salientar que a partir, principalmente, do início da década de 1960 a União Soviética passou a se defrontar com uma rival situada no seu campo ideológico. A China, então em rota de colisão com o Kremlin, disputava a hegemonia sobre os movimentos de contestação à ordem capitalista ao menos em três continentes: Ásia, África e América Latina. Os desafios postos pela China implicaram a necessidade de ações soviéticas com o intuito de conter a erosão da sua área de influência. Disso resultou que a URSS foi instada acompetir com a ex-aliada, em diferentes regiões do planeta. Mais uma vez, a política externa soviética impactava as finanças do país.

Angelo Segrillo problematiza o peso dos gastos em defesa na economia soviética e diferencia o impacto que os altos investimentos no setor militar provocaram na economia soviética na década de 1930 do ocorrido nas décadas de 1970 e 1980 . No primeiro período, o pesado investimento no setor industrial militar segundo o autor pode até haver estimulado certos segmentos econômicos, já nas décadas finais do regime soviético esse passivo pode haver se transformado em um fardo para aquela economia. Todavia, Segrillo relativiza essa questão, aponta as peculiaridades da economia soviética em relação à economia de mercado, afirma que o aparato industrial militar fazia parte do sistema tanto na era stalinista quanto no período pós-Stalin. Desse 
ponto de vista, questiona até onde o alto investimento no campo militar pode haver se tornado negativo para a economia soviética na conjuntura um pouco anterior à Perestroika ${ }^{16}$. De fato, esta é uma questão espinhosa e merece um debate mais alongado, mas, esse não é o escopo deste trabalho. Enfatiza-se a visão de Gorbachev de que o sistema militar consumia recursos indispensáveis para reformar a economia soviética e destaca-se as suas ações com o objetivo buscar uma solução que permitisse a redução dos gastos na área de defesa e nos campos a ela correlatos.

\section{O começo do fim?}

Existem diferentes abordagens para tratar as origens das profundas transformações ocorridas na União Soviética durante o período em que o país foi dirigido por Mikhail Gorbachev. Nas próximas páginas, algumas delas serão apresentadas de forma sumária com o intuito de compreender melhor aquele intrincado período histórico. Ressalta-se que o processo foi muito mais abrangente e que no exercício ora em desenvolvimento serão abordados apenas alguns pontos escolhidos conforme os critérios definidos segundo os propósitos em lide.

O historiador britânico Archie Brown defende a tese de que, em paralelo ao oficialismo governamental, ao longo das duas ou três décadas que antecederam às reformas implementadas por Gorbachev, um restrito círculo dirigente soviético manteve contato e trocou experiências com seus pares do Ocidente. Acrescenta Brown que alguns membros dessa elite dirigente viveram em países do mundo capitalista e foram marcados por suas experiências no exterior.

Para o autor, essa influência transnacional foi extremamente importante para a conformação de uma cultura política que possibilitou repensar a URSS e planejar as reformas que ela necessitava. Contudo, para Brown, se não é possível falar de uma revolução provocada por um homem, o que ocorreu na União Soviética somente foi possível porque Gorbachev possuía o poder e as condições para colocar a máquina do PCUS (Partido Comunista da União Soviética) e as instituições do Estado a serviço desses projetos. Segundo Brown, sem esse poder, aquelas influências dificilmente resultariam em algo concreto, uma vez que a rígida hierarquização institucional existente no país bloqueava qualquer possibilidade de mudança que não fosse pelo alto ${ }^{17}$.

Gorbachev assumiu o posto de Secretário Geral do Partido Comunista da União Soviética em março de 1985, apenas 24 horas após a morte de seu antecessor, Konstantin Ustínovitch Tchernenko. Para Daniel Aarão Reis Filho, a rapidez na escolha do novo Secretário Geral do PCUSS foi uma decorrência do fato de que ele já governava antes mesmo de ser formalmente escolhido. $\mathrm{O}$ autor lembra ainda que desde o agravamento da doença de Brejnev, o país foi (des)governado por personagens minguantes, doentes, mantidos à custa 
de altas dosagens de medicamentos. Havia pressa e, conforme indica Reis Filho, Gorbachev vinha com muita ambição de mudar. Não estava só, era a expressão da vontade de mudar que se formou até nas altas esferas do poder, pois mesmo nesses círculos restritos entendia-se que ou a União Soviética mudava ou deixava de ser grande potência ${ }^{18}$.

Gorbachev foi eleito pela unanimidade dos membros do Politburo e do Comitê Central. No entanto, o novo líder era muito mais reformista do que os colégios que o escolheram. É verossímil se supor que o novo Secretário Geral foi muito além do que ele mesmo pretendia. Uma vez desencadeado o processo de reformas, ele gerou efeitos inesperados pelo próprio criador. Desses efeitos indesejados, a desintegração da União Soviética foi o maior acontecimento ${ }^{19}$.

\section{Mudar a política externa da URSS}

Ao assumir o governo da União Soviética, Gorbachev pretendia imprimir mudanças que possibilitassem a retomada do crescimento econômico do país, que experimentava a redução no seu ritmo já havia três décadas. Assim, esperava também promover a melhoria das condições de vida da população. Naquele contexto, para Gorbachev era imperativo mudar a política externa do país, chegar a um acordo com os EUA e por um fim à Guerra Fria. O novo líder soviético estava convencido que a corrida armamentista derivada daquele conflito global privava o Estado soviético de vultosos recursos para o desenvolvimento da sua economia.

Com essa convicção, pouco após assumir as suas funções, o novo secretário do PCUS iniciou a substituição das personagens centrais na elaboração da política externa do país. Para ele sem esses deslocamentos estratégicos, o poder de elaboração da política externa continuaria nas mãos daqueles que haviam cristalizado uma posição que precisava ser revertida. Assim, ainda em meados de 1985, transferiu Andrei Gromiko, personagem central na elaboração da política externa soviética das últimas três décadas, para a função de presidente do Soviete Supremo e nomeou Eduard Shevardnadze para o Ministério das Relações Exteriores. Gorbachev sabia que era prudente não confrontar a influência de Gromiko e, com isso em mente, lhe conferiu um posto de honra, mas em grande parte decorativo e abriu caminho para as mudanças que considerava inadiáveis. À época, Shevardnadze foi considerado inexperiente, mas Gorbachev queria uma pessoa da sua confiança pois estava convencido de que somente assim poderia efetuar as mudanças tão necessárias ao seu país no campo das relações internacionais.

A seguir essa linha de conduta, em março de 1986, Gorbachev substituiu Boris Ponomarev, que ocupava a função de chefe do departamento de assuntos internacionais do Comitê Central do PCUS, por Anatoli Dobrynin, que havia sido embaixador soviético em Washington por 24 anos. Na sequência, substituiu Konstantin Russakov, que ocupava a chefia do Departamento de Países 
Socialistas do Comitê Central do PCUS, por outro aliado, Vadim Medvedev. Ainda no início de 1986, designou Anatoli Chernaiev como seu auxiliar no campo da política externa. Gorbachev trouxe para uma esfera de poder mais próxima a ele o diretor do Imemo (Instituto de Relações Internacionais de Moscou), Aleksander Iakovlev, que havia sido por anos embaixador no Canadá. Iakovlev foi conduzido ao Imemo por Yuri Andropov, a pedido de Gorbachev, e era um colaborador pessoal do novo chefe de Estado desde 1983.

Por fim, quando, em maio de 1987, um jovem alemão ocidental invadiu o sistema de defesa aéreo soviético sem ser detectado e pousou incólume próximo à Praça Vermelha, Gorbachev encontrou motivos mais do que suficientes para substituir o ministro da defesa, Sergei Sokolov, pelo general Dimitri Iazov. Esse conjunto de mudanças na equipe que elaborava a política externa da URSS foi de fundamental importância para a definição de novos rumos para o país ${ }^{20}$.

Gorbachev estava convencido de que precisava mudar a política externa de forma a construir as condições necessárias às reformas internas de que o país tanto carecia. Desse ponto de vista, era necessário gastar menos com a máquina de guerra decorrente da Guerra Fria, com o intuito de poupar recursos e destiná-los à promoção das reformas. Mais do que isso, Gorbachev acreditava que era necessário conquistar a confiança de governos e banqueiros internacionais para conseguir os recursos que ele precisava para a concretização dos seus ambiciosos planos. Ao mesmo tempo, precisava iniciar as reformas internas para mostrar ao povo soviético e ao mundo que as suas intenções eram reais e não mero discurso ideológico.

Gorbachev impressionou ao mundo com sua jovialidade e a rapidez nas ações políticas. Logo ao ser empossado procurou sinalizar aos dirigentes das potências estrangeiras que buscava o diálogo e a conciliação. O novo líder soviético ganhou a atenção da mídia internacional ao representar a diferença entre o esperado e o acontecido. Esperava-se um governante soviético idoso, circunspecto, um político soviético da velha estirpe dos homens do Kremlin. De certa forma, essa expectativa era produto da realidade soviética, mas em parte era resultado da construção do perfil dessas lideranças pela mídia internacional. Porém, Gorbachev era jovem, disposto, possuía, aos olhares da imprensa internacional, um charme, complementado pelo de sua esposa Raíssa. Assim, Gorbachev conquistou a mídia e a opinião pública que ele soube seduzir, mas talvez tenha sido arrebatado pelo glamour criado no exterior ao redor da sua personalidade, que era distinto da situação realmente existente na União Soviética. De fato, a mídia tornou Gorbachev uma espécie de astro da política internacional, a mídia o enaltecia, os banqueiros e governantes estrangeiros o elogiavam incansavelmente, mas, paradoxalmente, os recursos dos quais ele tanto precisava para executar os seus planos de reforma, somente vinham a conta-gotas, quando vinham. Gorbachev parecia aprisionado em uma trama associada à representação criada sobre a sua personalidade política. 
Aqueles que o louvavam em pouco ou nada o auxiliavam, pois esperavam o aprofundamento da crise que assolava a URSS para lucrarem ainda mais por intermédio da conquista dos mercados soviéticos em situação ainda mais favorável que aquelas acenadas por Gorbachev.

Não obstante todas essas dificuldades, Gorbachev surpreendeu ainda mais, quando desafiou na prática as propostas de redução de armamentos apresentadas por Reagan, superando-as, indo muito além, ao declarar a moratória unilateral de testes nucleares, a redução em 50\% dos armamentos estratégicos, a liquidação das armas nucleares até 2000, a redução dos mísseis intermediários e a adoção de rígidos controles sobre os armamentos convencionais ${ }^{21}$.

\section{Mudar a política interna}

Ao menos na fase inicial da administração Gorbachev, entre março e outubro de 1985, nota-se um grande descompasso entre as ações no campo das relações internacionais e as tímidas medidas adotadas internamente, que em muito repetiam experiências esboçadas por Nikita Kruschev, Alexei N. Kossiguin e mesmo durante o brevíssimo governo de Yuri Andropov. Contudo, essas medidas eram apenas paliativas, procuravam mostrar o que já era de domínio comum, mas poucos praticavam. Naquele contexto, conclamavase a população a mudar, afirmava-se que era necessário trabalhar mais e melhor, com honestidade e disciplina. Os novos dirigentes asseveravam que era preciso combater o alcoolismo, que atingia índices alarmantes no pais, renovar o patriotismo e adotar posturas que contribuíssem para melhorar a sociedade.

Não obstante, essas medidas estavam muito aquém dos desafios apresentados à superpotência decadente. Naquele período, foi maturado por Gorbachev e seus principais assessores um ousado projeto de mudanças econômicas, apresentado ao público sob o nome de Perestroika. O termo foi traduzido para a nossa língua com um sentido de reestruturação ${ }^{22}$. A Perestroika era resultado da necessidade do sistema face à intensificação de uma crise em gestação já havia um longo tempo ${ }^{23}$. Gorbachev publicou um livro onde defendia o projeto e afiançava sua importância para a União Soviética e para o mundo "Perestroika: novas ideias para o meu país e para o mundo". Seu livro tornou-se um sucesso de vendas, conquistou o público, foi traduzido rapidamente para dezenas de línguas, e virou um Best Seller mundial.

No entanto, apesar das mudanças na política internacional e a despeito das diretrizes definidas na Perestroika, a URSS parecia continuar à deriva. A crise aumentava e o país aparentava estar prestes a soçobrar. A Perestroika era uma reforma radical da economia que não se restringia aos marcos do sistema, mas tinha como objetivo transformá-lo. Para fazê-lo, Gorbachev tinha como foco duas tarefas centrais: primeiro, redirecionar a economia doméstica para 
o atendimento ao mercado consumidor. Isso implicava uma mudança nodal no planejamento econômico soviético desde as suas origens. Sublinha-se que nas últimas seis décadas sempre foram privilegiados os bens de produção. Adicionalmente, indicava-se como prioridade a realização de investimentos para o atendimento da área social, com enfoque principalmente em habitação e abastecimento; segundo, Gorbachev considerava fundamental mudar o sistema de gestão que havia se enraizado pelas mais diferentes áreas de produção da URSS.

Essas diretrizes implicavam a descentralização do processo decisório e a substituição do planejamento burocrático por outros instrumentos que possibilitassem a regulação da atividade econômica. Ao mesmo tempo, previase a extinção do controle das empresas pelos ministérios e a introdução de alguns mecanismos de mercado que passariam a atuar como reguladores dessas atividades. Todavia, como salienta Lenina Pomeranz, esse mercado era regulado por intermédio dos instrumentos de política econômica dirigidos pelo Estado ${ }^{24}$.

Entre 1987 e 1991, Gorbachev e a sua equipe tinham que se equilibrar para, de um lado, atender à demanda social reprimida por décadas, que vinha à tona estimulada pela abertura política e econômica impressa ao país. Aparentemente, os novos dirigentes pretendiam a transformação do modelo socialista soviético, de forma a torná-lo mais produtivo, democrático e competitivo. De outro, com a liberdade de expressão e de organização concedida pelo alto e estimulada tanto por forças endógenas quanto exógenas, a oposição tornava-se cada vez mais robusta e alguns setores passaram a propugnar o abandono do socialismo e o redirecionamento abrupto da União Soviética em direção a uma sociedade nos moldes liberais.

Nessa fase de experimentação de um modelo transitório, os resultados nem sempre eram promissores, como pretendiam os arquitetos da Perestroika, pois havia muita resistência inercial em diferentes segmentos da sociedade, o que dificultava "mover a montanha" como asseverou Abel Aganbegyan ${ }^{25}$. Naquele contexto, deu-se a redução dos mecanismos estatais de comando da economia por intermédio da Perestroika. Em paralelo, como reverberação da Glasnost, houve a restrição do poder político do próprio Gorbachev, derivada da abertura política, da transparência e do estímulo à crítica ao sistema pelos cidadãos.

A combinação dessas duas linhas de atuação de forma simultânea criava dificuldades quase intransponíveis para o governo. Por vezes, a economia não funcionava de modo conveniente e daí resultava a falta de produtos, porque eles não haviam sido produzidos em quantidades adequadas, estavam a ser desviados ou açambarcados. Como resultado dessa desorganização da economia, da emergência de práticas ilícitas por agentes do Estado e cidadãos, ou por equívocos cometidos pelos novos gestores, os preços disparavam e a inflação ganhava corpo. Logo, a população, que, a princípio havia depositado 
grandes esperanças nas transformações propostas por Gorbachev, tendia a criticar o governo e a aderir à oposição liberal ou às forças que pretendiam o retorno ao passado recente. Nessa conjuntura, a partir de 1989 começava a haver uma grande erosão na base de sustentação de Gorbachev.

Alex Pravda afirma que o colapso da União soviética foi resultado principalmente de fatores domésticos. Para o autor, as novas elites emergentes no clima liberal da Perestroika aproveitaram-se dos movimentos nacionalistas em efervescência para conquistar poder às expensas do Kremlin, que se encontrava fragilizado, como resultado dos enormes problemas econômicos e das divisões políticas. Nesse processo interno, Pravda salienta que as questões internacionais, relacionadas ao fim da Guerra Fria, desempenharam um papel secundário, mas não desprezível. Segundo o autor, esses fatores contribuíram para a aceleração do processo e para que ele se desse de forma pacífica ${ }^{26}$. Pravda considera que o colapso da União Soviética está associado a dois fatores correlacionados: a transformação do regime comunista e a desintegração da União altamente centralizada. Para ele, a condução da mudança do regime ocorreu pelo alto, quando o próprio Kremlin dirigiu um processo radical de mudança que transcendia o regime comunista. Já a união haveria sido minada a partir de baixo, quando as pequenas repúblicas bálticas, em uma primeira fase, começaram a exigir soberania (1989-1990) e, depois, a Ucrânia e a Rússia declararam a sua soberania (1990-1991).

Em meio a esse conturbado cenário pelo qual passava a União Soviética, Boris Yeltsin foi eleito por meio do voto popular, como o primeiro presidente da República da Rússia, em junho de 1991. Yeltsin, que havia se tornado desafeto e rival de Gorbachev, durante a sua campanha, defendeu abertamente os movimentos nacionalistas e separatistas e o aprofundamento das mudanças econômicas em direção ao capitalismo; ao lutar para reduzir ou extinguir o controle do Kremlin sobre as repúblicas, propiciou o entrelaçar dos movimentos nacionalistas com a disputa pelo poder central. A crise econômica persistente e a crescente polarização política tornaram muito mais difícil para Gorbachev manter a sua linha de reformas de caráter mais centrista.

A partir de agosto de 1991, após o fracasso do golpe contra Gorbachev, planejado inclusive por alguns homens por ele indicados para o governo, a sua margem de manobra ficou ainda mais reduzida. Seu principal rival político postou se na linha de frente contra o golpe e capitalizou aquele momento para alavancar ainda mais o seu prestígio político. Após o golpe ser debelado, Gorbachev se viu obrigado a agradecer ao rival em público, por supostamente haver salvo o regime que Yeltsin estava a demolir. Gorbachev saiu muito enfraquecido politicamente desse episódio e a sua capacidade de influenciar a opinião pública soviética se reduzia dia após dia, enquanto a popularidade do antagonista Yeltsin disparava. Nessas condições, Gorbachev não mais conseguia salvar o regime que ele defendia e muito menos podia chegar a um 
acordo com os adversários sobre a União ${ }^{27}$. Era o prenúncio do início do fim e a União Soviética começava a colapsar.

A questão das nacionalidades foi considerada como um problema insolúvel desde o período de Stalin. Há divergências sobre o assunto, mas, de modo dominante, não se via uma solução a curto ou médio prazo para o problema. A URSS havia assumido o controle dos domínios do antigo Império czarista. Inicialmente, em meio à efervescência da Revolução Bolchevique, acenou-se com a autodeterminação dos povos. Contudo, com o desencadear da guerra Civil e, posteriormente, com o advento do stalinismo, as expectativas de maior autonomia das nacionalidades foram frustradas e as lutas pela sua conquista foram tratadas como contrarrevolucionárias e reprimidas com brutal truculência. Durante todo o período stalinista, não houve espaço para expressão dos anseios dos povos que formavam o imenso império multiétnico da URSS ${ }^{28}$.

A despeito disso, após a morte de Stalin e, principalmente, após as crises de 1956, uma precária autonomia cultural e restritas possibilidades de autogoverno foram concedidas aos grupos minoritários. Naquele contexto de reformas e de democratização controlada pelo alto, conforme propugnado por Kruschev, alargaram-se os mecanismos de cooptação das elites nacionais locais. Nesse processo, segmentos das elites podiam atuar na administração pública e no partido em nível regional. Aos não russos e, em particular, aos não eslavos, havia barreiras quase intransponíveis, que impossibilitavam o acesso aos postos superiores do governo central. Essa estrutura, aliada ao sistema repressivo, manteve o problema nacional sob controle no período que se sucedeu à morte de Stalin ${ }^{29}$.

Segundo Bertonha, essa nova situação de certa estabilidade não implicava a inexistência de um problema nacional. Segundo o autor, em termos jurídicos, havia autonomia territorial para as quinze repúblicas. Porém, na sociedade soviética, eram costumeiras as queixas em consequência de tratamento desigual conferido os não russos $\mathrm{O}$ autor pondera que alguns observadores do período consideravam altas as possibilidades de que o denominado império soviético pudesse vir a ruir em consequência das revoltas dos povos dominados, assim como aconteceu com os impérios da França e da Grã-Bretanha na África e na Ásia ${ }^{30}$. Apesar disso, Bertonha considera que, à exceção dos países bálticos, não havia propostas separatistas mais sérias antes de 1988 ou 1989.

Para Bertonha, os movimentos nacionalistas que se desenrolaram no interior da União Soviética buscavam mais autonomia em relação a Moscou. $\mathrm{O}$ autor sublinha que em geral esses movimentos apoiavam Gorbachev contra a burocracia do partido. Dessa maneira, inicialmente não havia a intenção de se desligar da URSS. Todavia, com o desenvolvimento da crise econômica que assolou o país, cresceu o descontentamento social e sobreveio o caos político. Nessa trama que enredava cada vez setores mais amplos da sociedade 
soviética, a situação se deteriorou rapidamente, de tal forma que, entre 1989 e 1991, cresceram os movimentos independentistas nas repúblicas.

Dessa perspectiva, é preciso considerar outro fator de grande relevância. Muitos desses movimentos pela independência das repúblicas ganharam dimensão após os eventos que levaram à queda dos chamados regimes comunistas na Europa Oriental. As revoluções conservadoras ocorridas ao final de 1989, a queda do Muro de Berlim e depois a reunificação da Alemanha sem que houvesse a intervenção do Exército Soviético foram interpretadas como um sinal de que Gorbachev não empregaria a força militar para manter o controle das regiões sob o domínio soviético. Como resultado dessa percepção, os movimentos independentistas começaram a agir, a experimentar os limites do governo e a avaliar como ele agiria em relação às repúblicas. A considerar que passada a euforia dos primeiros anos revolucionários, ao menos em certa medida era a força militar que mantinha as republicas unidas na URSS. Quando ficou evidente que não haveria intervenção militar, a pressão pela independência ganhou novo fôlego e se tornou incontrolável.

Do caos em que se encontrava a URSS, emergia uma nova Rússia. Nela, a mobilização do nacionalismo russo por Yeltsin gerava tensões nas outras repúblicas. Na URSS, a Rússia, apesar de ser a maior das repúblicas soviéticas, estava subordinada ao poder central como todas as outras, mas, naquela situação de instabilidade, a nova Rússia comandada por Yeltsin buscava rever as fronteiras entre as antigas partes da URSS, assim como as relações econômicas e militares entre elas. Isso deu ainda mais força às pressões por independência que, agora, circulavam por toda a URSS. Entre agosto e setembro de 1991, quase todas as ex-repúblicas, inclusive as eslavas, como a Ucrânia e a Bielorrússia, proclamaram a sua independência ${ }^{31}$. Gorbachev assistia impotente ao desmantelamento da URSS, uma vez que o seu poder real se esvaía enquanto as forças agregadas a Yeltsin ganhavam vigor e cresciam a passos largos.

Nesse percurso, em 8 de dezembro de 1991, foi realizada, em Minsk, uma reunião com os dirigentes das três repúblicas eslavas (Rússia, Ucrânia e Bielorrússia), quando decidiram extinguir a URSS e criar a Comunidade de Estados Independentes (CEI), da qual poderiam participar as repúblicas que até então compunham a URSS. Gorbachev não foi convidado a participar da reunião. Assim, a Federação Russa tornava-se a sucessora da União Soviética. Gorbachev denunciou essa decisão como ilegal, mas pouco pode fazer para impedir os seus desdobramentos, pois no dia 12 seguinte o Supremo Soviete ratificou o acordado. Em 21 de dezembro do mesmo ano, Gorbachev recebeu um comunicado de que, em uma reunião realizada em Alma-Atma (Cazaquistão), com a participação de 11 repúblicas da ex-União Soviética, havia sido formalizada uma nova comunidade. As lideranças daquelas repúblicas sublinhavam a extinção da URSS. Nessa conjuntura extremamente adversa, Gorbachev renunciou à presidência da URSS em 25 de dezembro de $1991^{32}$. 
Com o fim da URSS, havia sido posto termo a uma era; definitivamente, a Guerra Fria havia sido superada. Naquele contexto, a dimensão das perdas geopolíticas russas com o fim da União Soviética foi incomensurável. De um lado, Yeltsin tratou rapidamente de apropriar-se de toda a rede de embaixadas e representações diplomáticas soviéticas espalhadas pelo mundo e de garantir a representação da Rússia no Conselho de Segurança da ONU como sucessora da URSS; buscou ainda manter o controle sobre os arsenais nucleares e as forças militares de elite e incorporar os símbolos de poder da antiga potência, incluindo-se o próprio Kremlin. Mas, de outro, a nova Rússia viu desaparecer o seu prestígio e ser reduzida imensamente a sua capacidade de atuação e o seu reconhecimento como potência global. Enfim, não mais havia uma segunda potência global que pudesse ao menos teoricamente se rivalizar com os EUA.

Naquele cenário, as fronteiras russas recuaram de forma dramática, de tal modo que em 1992 podiam ser, grosso modo, equiparadas às fronteiras do império Russo anteriores ao século XIX. Conforme aponta Bertonha, no Cáucaso, elas chegaram aproximadamente onde estiveram no início do século XIX. Na Ásia Central, equivaliam às fronteiras de meados daquele mesmo século. Talvez no caso mais emblemático, a fronteira europeia russa retrocedeu aos marcos da época de Ivã, o Terrível, no século XVI. Assim, quatro séculos de expansão imperial desapareceram ${ }^{33}$.

Como resultado da independência das repúblicas soviéticas, o território controlado por Moscou foi redimensionado de 22,4 para 17 milhões de $\mathrm{km}^{2}$, o equivalente a uma perda de aproximadamente um quarto do antigo território. Em termos populacionais, os prejuízos foram ainda mais dramáticos. Dos cerca de 290 milhões de habitantes da antiga URSS, a Rússia recuou para cerca de 150 milhões, o que representou uma redução populacional muito próxima da metade do que apresentava a antiga União Soviética.

André Gerrits ${ }^{34}$ estabeleceu uma comparação em termos geopolíticos entre a Rússia e o antigo Império Russo. Segundo os resultados apresentados pelo autor, é perceptível o drástico encolhimento da nova Rússia. Gerrits ressalta que o império czarista controlava no início do século $\mathrm{XX}, 17 \%$ da área, 9,8\% da população e 9,4\% do PIB mundial, enquanto a Rússia, em 1999, estava reduzida a apenas $13 \%$ da área, $2,5 \%$ da população e $1,6 \%$ do PIB global. Adicionalmente, Gerrits aponta o problema demográfico russo, com tendência ao encolhimento da população, que, segundo o autor, haveria perdido três milhões de habitantes entre 1992 e 2000. Enfatiza que se não fosse pela imigração a situação seria ainda pior. Ressalta a queda no padrão de saúde, com o aumento das taxas de mortalidade e queda nos índices de natalidade. Conforme Gerrits, em 20 anos a população poderá cair para 135 milhões e em um cenário mais pessimista poderá estar abaixo de 100 milhões em $2050^{35}$.

Uma análise um pouco mais detalhada da situação geopolítica da Rússia contemporânea revela um quadro ainda mais preocupante. A independência 
das antigas repúblicas simplesmente destruiu o sistema de proteção construído ao longo dos períodos imperial e soviético. Dessa forma, a Rússia teve as suas fronteiras expostas em meio a um contexto internacional bastante conturbado. No Ocidente, apesar do final da Guerra Fria, os EUA e os seus principais associados decidiram não apenas manter a Otan, quando a rival que havia justificado a sua criação não mais existia, como trataram de expandi-la. Mais que isso, incorporaram à aliança militar do Ocidente grande parte dos países que compunham a área de influência soviética na Europa Oriental e ex-repúblicas soviéticas.

Além de perder antigas áreas fundamentais à proteção das suas fronteiras naturais, a Rússia se deparou com o avanço das fronteiras dos antigos adversários $^{36}$. Em paralelo, nas suas fronteiras ao Sul cresceram as agitações entre os povos de predomínio muçulmano, em parte estimuladas por ações dos EUA. No Oriente, havia descordos sobre questões fronteiriças com a China, provenientes tanto de um passado mais distante quanto das últimas décadas. Em meio a esse cenário, o avanço dos EUA e dos seus aliados em áreas muito próximas às fronteiras russas tem gerado instabilidades principalmente em regiões de predomínio de populações islâmicas. Embora as populações islâmicas na atual Rússia tenham sido reduzidas de forma drástica, há ainda o risco de irradiação do problema, principalmente se considerarmos a questão das nacionalidades ainda não resolvidas, como são os casos da Geórgia e da Chechênia.

\section{Algumas conclusões provisórias e sujeitas a revisões}

Com a crise avassaladora que atingiu a URSS na segunda metade da década de 1980, a opção pelo desaquecimento da Guerra Fria não era apenas um desejo de Gorbachev, mas uma necessidade imperiosa, pois a economia soviética não mais suportava financiar os custos do conflito global. Com o insucesso das reformas, a URSS e os seus aliados europeus rumaram para uma crise que se expressou por intermédio das revoluções na Europa Oriental e pela queda do Muro de Berlim em 1989 e, posteriormente, pela desagregação do mundo soviético em 1991.

A considerar esses eventos, o motivo que havia justificado a criação da Otan não mais existia, pois nos anos iniciais da Guerra Fria, afirmava-se que a organização havia sido instituída para fazer frente à ameaça soviética à Europa Ocidental. Todavia, ao final daquele conflito global, ao contrário de extinguirem a aliança, os seus membros, liderados pelos EUA, colocaram a organização a serviço da expansão do modelo de sociedade capitalista estadunidense para as regiões anteriormente sob controle soviético.

Nessa nova conjuntura, em julho de 1997 a República Tcheca, a Hungria e a Polônia ingressaram na Otan. Em novembro de 2002, deu se a maior expansão da organização, com a adesão da Bulgária, da Eslováquia, 
da Eslovênia, da Estônia, da Latávia, da Lituânia e da Romênia. Ao longo da década de 1990 a Otan participou da Guerra do Golfo, de operações na exIugoslávia, na África e em outras regiões. No início do século XXI, participou do ataque e da invasão do Afeganistão e do Iraque. Hoje a Otan é composta pela Albânia, Alemanha, Bélgica, Bulgária, Canadá, Croácia, República Tcheca, Dinamarca, Eslováquia, Espanha, Estados Unidos, Estônia, França, Grã-Bretanha, Grécia, Holanda, Hungria, Islândia, Itália, Latávia, Lituânia, Luxemburgo, Noruega, Polônia, Portugal, Romênia e Turquia ${ }^{37}$.

Atualmente, EUA e Rússia mantém relações que oscilam da cordialidade em certos momentos, a disputas verborrágicas por intermédio da mídia e momentos de maior gravidade, quando efetivamente os interesses nodais desses dois Estados se confrontam em diferentes cenários do globo. Nesse campo, imperam incertezas, principalmente quando os atuais líderes das duas nações são personalistas, imprevisíveis e muitas vezes atravessam as fronteiras da responsabilidade política que deveriam preservar.

\section{Referências}

AGANBEGYAN, Abel. Movendo a montanha. São Paulo: Best Seller, 1990.

ANDERSON, Perry. O fim da história: de Hegel a Fukuyama. Rio de Janeiro: Jorge Zahar, 1992.

BACEVICH, Andrew J. . American empire: the realities and consequences of U.S. diplomacy. Cambridge: Harvard University press, 2002.

BERTONHA, João Fábio. Rússia - Ascensão e Queda de Um Império: uma história geopolítica e militar da Rússia, dos Czares ao Século XXI. Curitiba, Juruá, 2009.

BRADLEY, Mark P. . Decolonization, the global South, and the Cold War, 1919-1962. In: LEFFLER \& WESTAD. The Cambridge History of the Cold War. New York: Cambridge University Press, 2010, v.1, p. 464-485.

BROWN, Archie. The Gorbachev revolution and the end of The Cold War. In: LEFFLER \& WESTAD. The Cambridge History of the Cold War. New York: Cambridge University Press, 2010, v. 3, p. 244-266.

DAWISCHA, Karen; PARROTT, Bruce. Russia and the new states of Eurasia. The politics of upheaval. Cambridge: Cambridge University Press, 1994.

FUKUYAMA, Francis. After the End of History. Open Democracy, 2006. https://www. opendemocracy.net/democracy-fukuyama/revisited_3496.jsp (acesso 20 jan 2017).

FUKUYAMA, Francis. End of History? National interest, Summer, 1989 p. 3-18; The end of History and the last man. New York: Free Press, 1992.

FUKUYAMA, Francis. Reflections on the end of History, five years later. History \& Theory, v.34, May, 1995, p. 27-43.

GERRITS, André W. M. . Hegemonia americana e multipolaridade: o sistema internacional no século XXI - caso russo. IN: VIZENTINI, Paulo ; WIESEBRON, Marianne. Neohegemonia americana ou multipolaridade? Polos de poder e sistema internacional. Porto Alegre: UFRGS Editora, 2006, p. 173-197. 
GORBACHEV, Mikail Perestroika. Novas ideias para o meu país e o mundo, Rio de janeiro: Best Seller, 1987.

HOBSBAWM, Eric, J. . Era dos extremos: o breve século XX: 1914-1991. São Paulo: Cia. das letras, 1995.

HUNTINGTON, Samuel. No exit: the errors of endism. National Interest, 1989, Fall, p. 3-11;

IKENBERRY, G. JOHN. The restructuring of the international system after the Cold War. IN: LEFFLER \& WESTAD. The Cambridge History of the Cold War. New York: Cambridge University Press, 2010, v.3, p. 535-556.

LATHAM, Michael. The Cold War in the Third World, 1963-1975. In: LEFFLER \& WESTAD. The Cambridge History of the Cold War. New York: Cambridge University Press, 2010, v.2, p. 258-280.

MUNHOZ, Sidnei J. . Imperialismo e Anti-imperialismo, Comunismo e Anticomunismo durante a Guerra Fria. Revista Esboços, Florianópolis, v. 23, n. 36, p. 452-469, fev. 2017.

MUNHOZ, Sidnei J. . Organização do Tratado do Atlântico Norte. In: TEIXEIRA DA SILVA, Francisco C. et alii (orgs). Atlântico: a história de um oceano. Rio de Janeiro: Civilização Brasileira, 2013, p. 433-461.

NOVE, ALEC . The rising of non-Leninist thinking on the economy. in: BROWN, Arch. Demise of Marxixsm-Leninism in Russia, 1997.

NOVE, Alec. The economics of feasible socialism revisited. London: Taylor \& Francis, 1991, 2nd edition.

NOVE, Alec. Stalinism and After. New York: George Allen \& Unwin, 1975, p.151-156.

POMERANZ, Lenina (org). Perestroika: desafios da transformação social na URSS. São Paulo, Edusp, 1990.

PRAVDA, Alex. The Collapse of Soviet Union 1990-1991. In: LEFFLER \& WESTAD. The Cambridge History of the Cold War. New York: Cambridge University Press, 2010, v. 3, p. 356-377.

REIS FILHO, Daniel Aarão. Uma revolução perdida: a história do socialismo soviético. São Paulo: fundação Perseu Abramo, 1997.

SEGRILLO, Angelo. O Declínio da União soviética. Rio de Janeiro: Record, 2000.

\section{Notas}

1 Sublinha-se que o chamado sistema bipolar vigente durante a Guerra Fria, em especial passada a sua primeira fase que se prolongou entre 1947 e 1953, nunca foi plenamente bipolar, pois havia dissensões no interior de cada um dos blocos, que por vezes culminava em rupturas e conflitos em seu interior.

2 IKENBERRY, G. JOHN. The restructuring of the international system after the Cold War. IN: LEFFLER \& WESTAD. The Cambridge History of the Cold War. New York: Cambridge University Press, 2010, v.3, p. 535-556.

3 FUKUYAMA, Francis. End of History? National interest, Summer, 1989 p. 3-18; The end of History and the last man. New York: Free Press, 1992. Fukuyama foi extremamente criticado à época por autores de diferentes correntes de pensamento. Apenas a título ilustra- 
tivo destaca-se HUNTINGTON, Samuel. No exit: the errors of endism. National Interest, 1989, fall issue, p. 3-11; ANDERSON, Perry. O fim da história: de Hegel a Fukuyama. Rio de Janeiro: Jorge Zahar, 1992. Fukuyama ao longo dos anos procurou responder aos seus críticos por intermédio de novos artigos onde parcialmente revisava as suas teses iniciais. FUKUYAMA, Francis. Reflections on the End of History, Five Years Later. History \& Theory, v.34, May, 1995, p. 27-43; After the End of History. Open Democracy, 2006. https:// www.opendemocracy.net/democracy-fukuyama/revisited_3496.jsp (acesso 20 jan 2017).

4 NOVE, Alec. The economics of feasible socialism. London: George Allen \& Unwin, 1983; REIS FILHO, Daniel Aarão. Uma revolução perdida: a história do socialismo soviético. São Paulo: Fundação Perseu Abramo, 1997, p. 225.

5 REIS FILHO, Daniel Aarão. Uma revolução perdida: a história do socialismo soviético. São Paulo: Fundação Perseu Abramo, 1997, p. 223, citando NOVE.

6 SEGRILLO, Angelo.O Declínio da União soviética. Rio de Janeiro: Record, 2000, p. 191192

7 GORBACHEV, Mikail Perestroika. Novas ideias para o meu país e o mundo. Rio de janeiro: Best Seller, 1987, p. 17

8 POMERANZ, Lenina (org). Perestroika: desafios da transformação social na URSS. São Paulo: Edusp, 1990, p. 12-13

9 NOVE, Alec The economics of feasible socialism revisited. London: Taylor \& Francis, 1991, 2nd edition.

10 NOVE, ALEC . The rising of non-Leninist thinking on the economy. in: BROWN, Arch. Demise of Marxixsm-Leninism in Russia, 1997, p 41-50.

11 HOBSBAWM, Eric, J. . Era dos extremos: o breve século XX: 1914-1991. São Paulo: Cia. das letras, 1995.

12 NOVE, Alec. Stalinism and After. New York: George Allen \& Unwin, 1975, p. 151-156.

13 REIS FILHO, Daniel Aarão. Uma revolução perdida: a história do socialismo soviético. São Paulo: Fundação Perseu Abramo, 1997, p. 216.

14 NOVE, Alec The economics of feasible socialism revisited. London: Taylor \& Francis, 1991, 2nd edition, p. 78.

15 LATHAM, Michael. The Cold War in the Third World, 1963-1975. In: LEFFLER \& WESTAD. The Cambridge History of the Cold War. New York: Cambridge University Press, 2010, v.2, p. 258-280; BRADLEY, Mark P. . Decolonization, the global South, and the Cold War, 1919-1962. In: LEFFLER \& WESTAD. The Cambridge History of the Cold War. New York: Cambridge University Press, 2010, v.1, p. 464-485, em especial, p. 480. MUNHOZ, Sidnei J. . Imperialismo e Anti-imperialismo, Comunismo e Anticomunismo durante a Guerra Fria. Revista Esboços, Florianópolis, v. 23, n. 36, p. 452-469, fev. 2017.

16 SEGRILLO, Angelo. O Declínio da União soviética. Rio de Janeiro: Record, 2000, principalmente p. 124-135.

17 BROWN, Archie. The Gorbachev revolution and the end of The Cold War. In: LEFFLER \& WESTAD. The Cambridge History of the Cold War. New York: Cambridge University Press, 2010, v 3, p. 244-266.

18 REIS FILHO, op. cit, p. 231.

19 BROWN, A. . op. cit, p. 247-248. 
20 BROWN, A. . op. cit., p. 248-251.

21 REIS FILHO, op. cit, p. 232.

22 REIS FILHO, op. cit, p. 232-233.

23 POMERANZ, Lenina. Op. cit. , p. 12.

24 POMERANZ, Lenina. Op. cit. , p. 27.

25 AGANBEGYAN, Abel. Movendo a montanha. São Paulo: Best Seller, 1990.

26 PRAVDA, Alex. The Collapse of Soviet Union 1990-1991. In: LEFFLER \& WESTAD. The Cambridge History of the Cold War. New York: Cambridge University Press, 2010, v. 3, p. 356-377.

27 PRAVDA, Alex. Op. cit., p. 357.

28 Sublinha-se nesse quesito o emprego de império, considerando-se a esfera de influência soviética como um império informal. Observa-se que muitos autores adotam uma perspectiva similar para se referir ao controle dos EUA sobre a sua área de influência.

29 DAWISCHA, Karen; PARROTT, Bruce. Russia and the new states of Eurasia. The politics of upheaval. Cambridge: Cambridge University Press, 1994, p. 13-17.

30 BERTONHA, João Fábio. Rússia - Ascensão e Queda de Um Império - Uma História Geopolítica e Militar da Rússia, dos Czares ao Século XXI. Curitiba, Juruá, 2009.

31 BERTONHA, João Fábio. Op. cit.

32 REIS FILHO, Daniel A. . Op. cit, p. 267.

33 BERTONHA, João Fábio. Op. cit.

34 GERRITS, André W. M. . hegemonia americana e multipolaridade: o sistema internacional no século XXI - caso russo. IN: VIZENTINI, Paulo ; WIESEBRON, Marianne. Neohegemonia americana ou multipolaridade? Polos de poder e sistema internacional. Porto Alegre: UFRGS Editora, 2006, p. 173-197, em especial p. 175.

35 GERRITS, André op. cit., p. 176.

36 BACEVICH, Andrew J. . American empire: the realities and consequences of U.S. diplomacy. Cambridge: Harvard University Press, 2002.

37 MUNHOZ, Sidnei J. . Organização do Tratado do Attântico Norte. In: TEIXEIRA DA SILVA, Francisco C. et alii (orgs). Atlântico: a história de um oceano. Rio de Janeiro: Civilização Brasileira, 2013, p. 433-461.

Recebido em 21/10/2017

Aprovado em 08/12/2017 